Journal of Occupational Medicine and Environmental Health 2014; 27(4):583 - 590

6. Panduranga Kamath $M$, Vijendra Shenoy $S$, Suja Sreedharan, Kiran Bhojwani, Sujith Sam Mammen, Nazeem Abdul Majeed. Role of electronystagmography in balance disorders: A clinical study Indian Journal of Otology | July 2015

\section{| Vol 21 | Issue 3 |}

7. Simon.I.Angeli,

Sandra.Velandia,

Hillary.Snapp. Head-shaking nystagmus predicts greater disability in unilateral peripheral vestibulopathy American Journal of Otolaryngology-Head and Neck Medicine and Surgery 32(2011)522-527

\title{
NHIỄM HPV NGUY Cơ CAO TRÊN BÊNNH NHÂN CÓ TẾ BÀO ÂM ĐẠO CỔ TỬ CUNG BẤT THƯỜNG TẠI BỆNH VIÊ̂N PHỤ SẢN TRUNG ƯỚNG
}

\author{
Ngô Thị Thanh Hương ${ }^{1}$, Đào Thị Hoa ${ }^{2}$, Lê Hoàng ${ }^{3}$
}

\section{TÓM TẮT}

Mục tiêu: Xác định tỷ lệ nhiễm HPV nguy cơ cao trên bệnh nhân có tế bào âm đạo cổ tử cung bất thường và đối chiếu giữa kết quả HPV nguy cơ cao với kết quả tế bào âm đạo cổ tử cung bất thường. Đối tượng và phương pháp nghiên cứu: Nghiên cứu trên 259 phụ nữ đến khám tại khoa khám bệnh bệnh viện phụ sản Trung ương có xét nghiệm HPV nguy cơ cao và kết quả tế bào âm đạo CTC bất thường trong thời gian từ tháng 8/ 2020 đến tháng 4/ 2021. Kết quả nghiên cứu: Tuổi trung bình của phư nữ làm xét nghiệm là $38 \pm 9,1$; số phụ nữ trong độ tuổi từ 25 - 39 chiếm $52,9 \%$. Có $76,4 \%$ trường hợp bị nhiễm HPV trong đó: $37,1 \%$ nhiếm 1/12 Typ nquy cơ cao khác chiếm tỷ lệ cao nhất; $17,8 \%$ nhiễm Typ 16; 6,2\% nhiếm Typ 18; 15,4\% nhiếm từ 2 typ trở lên. Tỳ lệ tế bào âm đạo cổ tứ cung bất thường: $0,8 \%$ là ung thư tế bào vảy; $42,9 \%$ có tổn thương LSIL chiếm tỷ lê cao nhất; $18,5 \%$ là HSIL; $34,4 \%$ là tế bào phản ứng (ASC: $30,5 \%$ và AGC: $3,9 \%$ ). Có $69,6 \%$ tế bào ASCUS bi nhiễm HPV; $85,6 \%$ tế bào LSIL nhiễm HPV; $81,3 \%$ HSIL có nhiễm HPV và cả 2 trường hợp ung thư biểu mô vảy đều không nhiễm HPV.

Tưr khóa: Ung thư cổ tử cung, sàng lọc tế bào học phụ khoa, HPV

\section{SUMMARY \\ HIGH- RISK HPV INFECTION IN PATIENTS WITH ABNORMAL CERVICAL VAGINAL CELLS AT THE NATIONAL HOSPITAL OF OBSTETRICS AND GYNECOLOGY}

Objective: Determine the prevalence of high-risk $\mathrm{HPV}$ infection in patients with abnormal cervical vaginal cells and compare high- risk HPV results with abnormal cervical vaginal cytology results. Material and Methodology: Study on 259 women who visited the examination department at the National Hospital of Obstetrics and Gynecology with high- risk HPV test and

${ }^{1}$ Bệnh viện Sản Nhi Bắc Ninh

${ }^{2}$ Bệnh viện Phụ Sản Trung ương

${ }^{3}$ Bềnh viên Đa khoa Tâm Anh

Chịu trách nhiệm chính: Ngô Thị Thanh Hương

Email: ntthuong1607@gmail.com

Ngày nhận bài: 16.9.2021

Ngày phản biên khoa hoc: 11.11.2021

Ngày duyệt bài: 13.11.2021 abnormal cervical cell results during the period from $8 /$ 2020 to 4/2021. Result: The average age of women talking the test was $38 \pm 9,1$; the highest number of women aged $25-39$ accounted for $52,9 \%$. There were $76,4 \%$ cases of HPV infection in which: $37,1 \%$ infected with $1 / 12$ other high-risk types accounted for the highest rate; $17,8 \%$ infected with Type 16; 6,2\% infected with Type $18 ; 15,4 \%$ infected with 2 or more types. The percentage of abnormal cervical cells: $0,8 \%$ is squamous cell carcinoma; $42,9 \%$ had the highest percentage of LSIL lesions; $18,5 \%$ is HSIL; $34,4 \%$ were reactive cells (ASC: $30,5 \%$ and AGC: 3,9\%). There were $69,6 \%$ ASCUS cells infected with HPV; $85,6 \%$ of LSIL cells infected with HPV; $83,1 \%$ of HSIL had HPV infection and both squamous cell carcinoma cases were not infected with HPV.

Key words: Cervical cancer, gynecological cytology screening, HPV.

\section{I. ĐĂT VẤN ĐỀ}

Ung thư cổ tử cung ( UTCTC) là loại ung thư phổ biến, đứng thứ tư trong các loại ung thư ở nữ và thứ hai trong các loai ung thư phu khoa ${ }^{1,2}$. Nhiễm một hay nhiêu typ HPV nguy cơ cao là nguyên nhân gây ra sự biến đổi tế bào, trải qua giai đoạn tiên ung thư và dẫn đến UTCTC ${ }^{1}$. Quá trình tiến triển từ khi nhiễm HPV từ giai đoạn tiên ung thư đến UTCTC thường kéo dài từ 5 20 năm³ ${ }^{3}$ Ở Việt Nam đã có rất nhiều nghiên cứu về nhiễm HPV trong cộng đồng nhưng chưa có nhiều nghiên cứu về nhiễm HPV trên nhóm bệnh nhân làm xét nghiêm tế bào âm đạo. Nhằm xác định tỷ lệ nhiễm HPV ở các bệnh nhân có tế bào âm đạo cổ tử cung bất thường, chúng tôi tiến hành nghiên cứu này nhằm mục tiêu:" Xác định tỷ lệ nhiễm HPV nguy cơ cao trên bệnh nhân có tế bào âm đạo cổ tử cung bất thường và đối chiếu giữa kêt quả HPV nguy cơ cao với kết quả tế bào âm đạo cổ tử cung bất thường".

\section{II. ĐỐI TƯỢNG VÀ PHƯƠNG PHÁP NGHIÊN CỨU}

2.1. Đối tượng nghiên cứu: Phụ nữ đến khám bệnh tại Bệnh viện Phụ sản Trung ương phù hợp với tiêu chuẩn lựa chọn, tiêu chuẩn loại 
trừ dưới đây và đồng thuận tham gia vào nghiên cứu trong khoảng thời gian từ 8/2020 đến 4/2021.

2.1.1 Tiêu chuẩn lựa chon: Phụ nữ đến khám và điều trị có xét nghiệm HPV nguy cơ cao và kết quả tế bào âm đạo CTC bất thường: ASC (ASCUS, ASCUS - H), LSIL, HSIL, AGS (AUGUS, AIS), ung thư biểu mô vảy, ung thư biểu mô tuyến; Có đầy đủ thông tin hành chính; Đồng ý tham gia nghiên cứu.

2.1.2 Tiêu chuẩn loại trừ: Những bệnh nhân không đủ điều kiện trên; Đang mang thai; Đã cắt tử cung hoàn toàn hoặc cắt cụt CTC, đốt, LEEP hoặc khoét chóp CTC; Đã được chẩn đoán ung thu CTC.

2.2. Phương pháp nghiên cứu:

2.2.1. Thiết kế nghiên cứu: Nghiên cứu mô tả cắt ngang, lấy số liệu tiến cứu.

2.2.2. Cõ̃ mẫu:

$$
\mathbf{n}=\frac{\mathrm{z}_{1-\alpha / 2}^{2} \times \mathrm{p}(1-\mathrm{p})}{\mathrm{d}^{2}}
$$

Trong đó: $\mathrm{n}$ : Cõ̃ mẫu nghiên cứu

Z1-a/2: Hệ số giới hạn tin cậy, với $a=0,05 \rightarrow$ $Z_{1-\mathrm{a} / 2}=1,96$.

$p=0,732$ (Tỉ lệ nhiễm HPV trên tế bào học HSIL trong nghiên cứu của Trương Quang Vinh (2010) là $73,2 \%)^{4}$

d: Độ sai lệch mong muốn giữa tỉ lệ thu được từ mẫu và tỉ lệ thực của quần thể, chọn $\mathrm{d}=$ $1 / 10 p=0,0732$

Thay số, $\mathrm{n}=140$. Như vậy cõ mẫu nghiên cứu tối thiểu là 140 trường hợp có kết quả tế bào âm đạo cổ tử cung bất thường. Trong nghiên cứu này chúng tôi lấy được 259 bệnh nhân.

2.2.3. Các biến số nghiên cứu: Tuổi; Xét nghiệm tế bào âm đạo, cổ tử cung bất thường; Xét nghiệm HPV nguy cơ cao.

\section{KẾT QUẢ NGHIÊN CứU}

\section{Bảng 1: Tuổi của đôî tượng nghiên cứu}

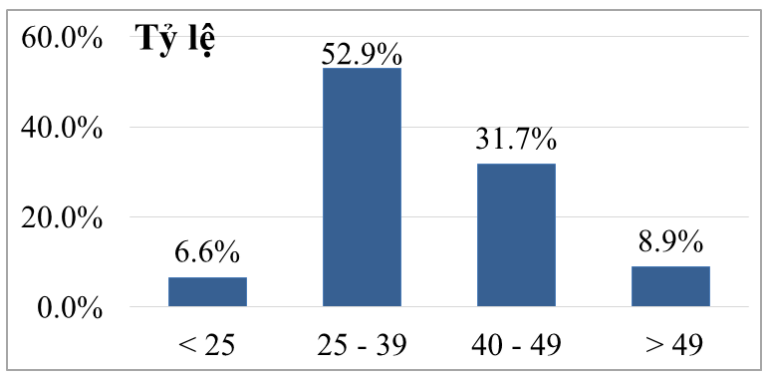

Nhóm tuổi có tỷ lệ cao nhất là từ 25 - 39 $(52,9 \%)$, tiếp đên là nhóm tuổi $40-49(31,7 \%)$, thấp nhất là nhóm tuổi < 25 (6,6\%). Tuổi trung bình là $38 \pm 9,1$.

Bảng 2. Tỷ lệ nhiếm HPV trong mẫu nghiên cứu

\begin{tabular}{|c|c|c|c|c|}
\hline \multicolumn{2}{|c|}{ KQ HPV } & $\mathbf{N}$ & $\mathbf{\%}$ & \\
\hline \multicolumn{2}{|c|}{ HPV âm tính } & 61 & 23,6 & \\
\hline \multirow{2}{*}{$\begin{array}{c}\text { HPV } \\
\text { dương }\end{array}$} & 16 & 46 & 17,8 & \multirow{2}{*}{ Tổng } \\
\cline { 2 - 4 } tính & 18 & 16 & 6,2 & 198 \\
\cline { 2 - 4 } & $1 / 12$ & 96 & 37,1 & $(76,4 \%)$ \\
\cline { 2 - 4 } & Đa nhiếm & 40 & 15,4 & \\
\hline \multicolumn{2}{|c|}{ Tống } & $\mathbf{2 5 9}$ & $\mathbf{1 0 0}$ & \\
\hline \multicolumn{2}{|c|}{} \\
\hline
\end{tabular}

Tỷ lệ nhiễm HPV là 76,4 \%. Nhiễm $1 / 12$ typ chiếm tỷ lệ cao nhất $37,1 \%$, nhiễm typ 18 chiếm tỷ lê thấp nhất $(6,2 \%)$. Nhóm đa nhiếm là nhóm nhiểm từ 2 Typ trở lên trong số Typ 16, Typ 18, $1 / 12$ Typ chiếm $15,4 \%$.

Bảng 3: Kêt quả tế bào âm đạo cổ tử cung bất thường :

\begin{tabular}{|c|c|c|c|c|}
\hline \multicolumn{2}{|c|}{} & $\mathbf{N}$ & $\mathbf{\%}$ & Tống \\
\hline \multirow{2}{*}{$\begin{array}{c}\text { TB phản } \\
\text { ứng }\end{array}$} & AGC & 10 & 3,9 & 89 \\
\cline { 2 - 4 } & ASC & 79 & 30,5 & $(34,4 \%)$ \\
\hline \multirow{2}{*}{$\begin{array}{c}\text { TB nghi } \\
\text { ngờ và } \\
\text { ung thư }\end{array}$} & ASCH & 9 & 3,5 & \\
\cline { 2 - 4 } & LSIL & 111 & 42,9 & 170 \\
\cline { 2 - 4 } & HSIL & 48 & 18,5 & $(65,6 \%)$ \\
\cline { 2 - 4 } & KBMV & 2 & 0,8 & \\
\hline \multicolumn{2}{|c|}{ Tống } & $\mathbf{2 5 9}$ & $\mathbf{1 0 0}$ & \\
\hline
\end{tabular}

- Tế bào phản ứng chiếm 34,4\% (AGC: $3,9 \%$, ASC: $30,5 \%$ )

- Tổn thương nội biểu mô vảy chiếm $61,4 \%$, trong đó LSIL chiểm tỷ lệ cao nhất là $42,9 \%$, HSIL chiếm $18,5 \%$.

- Có 2 trường hợp ung thư biểu mô vảy $(0,8 \%)$

Bảng 4: Tỷ lệ nhiếm HPV với tứng loại tế bào bất thường:

\begin{tabular}{|c|c|c|c|c|}
\hline \multirow{2}{*}{$\begin{array}{c}\text { Kết quả tế } \\
\text { bào học }\end{array}$} & \multicolumn{2}{|c|}{ Dương tính } & \multicolumn{2}{c|}{ Ãm tính } \\
\cline { 2 - 5 } & $\begin{array}{c}\text { Số } \\
\text { lượng }\end{array}$ & $\%$ & $\begin{array}{c}\text { Số } \\
\text { lượng }\end{array}$ & $\%$ \\
\hline AGC & 3 & 30 & 7 & 70 \\
\hline ASC & 55 & 69,6 & 24 & 30,4 \\
\hline ASCH & 6 & 66,7 & 3 & 33,3 \\
\hline LSIL & 95 & 85,6 & 16 & 14,4 \\
\hline HSIL & 39 & 81,3 & 9 & 18,8 \\
\hline KBMV & 0 & 0 & 2 & 100 \\
\hline Tống số & 198 & 76,4 & 61 & 23,6 \\
\hline \multicolumn{4}{|c|}{$\mathbf{P <} \mathbf{0 , 0 5}$} \\
\hline
\end{tabular}

Tỷ lê nhiếm HPV trên nhóm tế bào ASC là $69,6 \%$, trên nhóm LSIL là $85,6 \%$, nhóm HSIL có $81,3 \%$ nhiễm HPV, có 2 trường hợp ung thư biểu mô vảy đều không nhiễm HPV. Sự khác biệt có ý nghĩa thống kê $(p<0,05)$

Bảng 5: Mối liến quan giứa nhiễm HPV với tê bào âm đao cổ tư cung bất thường:

\begin{tabular}{|l|c|c|c|}
\hline & HPV (+) & HPV ( -) & \\
\hline TBH phản ứng & 58 & 31 & \\
$(29,3 \%)$ & $(50,8 \%)$ & \\
\hline
\end{tabular}




\begin{tabular}{|c|c|c|c|}
\hline $\begin{array}{c}\text { TBH bất } \\
\text { thường và } \\
\text { nghi ung thư }\end{array}$ & $\begin{array}{c}140 \\
(70,7 \%)\end{array}$ & $\begin{array}{c}30 \\
(49,2 \%)\end{array}$ & $\begin{array}{c}\text { OR=2,5 } \\
\mathbf{9 5} \% \mathbf{C I} \\
\mathbf{1 , 4}-\mathbf{4}, \mathbf{5}\end{array}$ \\
\hline Tổng & $\begin{array}{c}\mathbf{1 9 8} \\
(\mathbf{1 0 0} \%)\end{array}$ & $\begin{array}{c}\mathbf{6 1} \\
\mathbf{( 1 0 0 \% )}\end{array}$ & \\
\hline
\end{tabular}

Tốn thương tế bào bất thường và nghi ung thư tăng gấp 2,5 lần ở nhóm nhiểm HPV so với nhóm không nhiễm HPV.

Sự khác biệt có ý nghĩa thống kê $(O R=2,5$; 95\% CI: $1,4-4,5$ )

\section{BÀN LUÂ̂N}

Vê độ tuổi của nhóm bệnh nhân trong nghiên cứu. Trong nghiên cứu của chúng tôi, tuổi trung bình của mẫu nghiên cứu là $38 \pm 9,1$. Nhóm độ tuổi có kết quả tế bào âm đạo bất thường cao nhất là nhóm từ 25-39 tuổi chiếm tỉ lệ là $52,9 \%$, sau đó là nhóm tuổi từ 40- 49 chiếm $31,7 \%$, nhóm > 49 tuổi chiếm $8,9 \%$ và nhóm chiếm tỉ lệ thấp nhất là nhóm < 25 tuổi với 6,6 $\%$. Theo nghiên cứu của Thomas $\mathrm{C}$. Wright và cộng sự, một phần trong nghiên cứu đa trung tầm ATHENA năm 2013 ở Mỹ về xét nghiệm bộ đôi HR- HPV và PAP smear cho thây tỉ lệ bất thường cao nhất cũng rơi vào nhóm tuổi 30-39 chiếm $34,6 \%$, so với nghiên cứu của chúng tôi cũng có sự tương đồng 5 .

Về Tỷ lệ nhiễm HPV trong mẫu nghiên cứu: Trong nghiên cứu của chúng tôi, $76,4 \%$ có nhiễm HPV trong đó nhóm nhiếm 12 typ nguy cơ cao khác chiếm tỉ lệ cao nhất $37,1 \%$, nhóm chỉ nhiễm HPV Typ 16 chiếm 17,8\%, nhóm chỉ nhiễm HPV Typ 18 có tỷ lệ thấp nhất chiếm $6,2 \%$. Nhóm bệnh nhân đa nhiếm nghĩa là nhiếm HPV từ 2 typ trở lên trong số Typ 16, 18, $1 / 12$ Typ chiếm $15,4 \%$. Kết quả nghiên cứu của Phạm Thị Thanh Yên (2016) tại bệnh viện Phụ sản Trung Ương trên 237 bệnh nhân nhiếm HPV nguy cơ cao cũng cho kết quả tưỡng tự như nghiên cứu của chúng tôi về tỉ lệ nhiễm giữa các typ: Typ 16(16,46\%), Typ18(6,7\%), 1/12 Тyp $(62,45 \%)$, Đa nhiễm $(14,39 \%)^{6}$.

Tỷ lệ tế bào âm đạo cổ tử cung bất thường: Trong số 259 bệnh nhân có kết quả tế bào học bất thường và được xét nghiệm HPV thì có 2 trường hợp bị ung thư biểu mô vảy $(0,8 \%)$, tî lệ bất thường cao nhất ở nhóm LSIL chiếm $42,9 \% ; \mathrm{HSIL} 18,5 \% ; 34,4 \%$ tế bào phản ứng( ASC, AGC). Tỉ lệ bệnh nhân LSIL cao gấp 2,3 lần HSIL và gấp 55,5 lần ung thư biểu mô vảy. Nghiên cứu của chúng tôi không ghi nhận được trường hợp nào bất thường biểu mô tuyến. Trong nghiên cứu của Natacha (2017) tại Thái Lan với cõ mẫu là 62 bệnh nhân : ASCCUS có
36/62 trường hợp, LSIL 23/62 trường hợp, và có $3 / 62$ trường hợp HSIL7.Trong nghiên cứu của chúng tôi bệnh nhân được làm Thin prep nên tỷ lệ phát hiện LSIL sẽ cao hơn.

Tỷ lệ nhiếm HPV trên từng loại bất thường tế bào âm đạo cổ tử cung. Kết quả nghiên cứu cho thấy $81,3 \%$ bệnh nhân HSIL có nhiếm HPV và $85,6 \%$ bệnh nhân LSIL nhiếm HPV. Kết quả nghiên cứu của chúng tôi cũng có sự tương đồng với nhiều nghiên cứu khác trong và ngoài nước góp phần chứng minh HPV là nguyên nhân gần như duy nhất gây ung thư cổ tứ cung. Trong nghiên cứu của tác giả Lê Quang Vinh (2013), tỉ lệ nhiếm HPV ở nhóm bệnh nhân LSIL rất cao đạt $97,2 \%$, điều này theo chúng tôi, gợi ý rằng có độ tin cậy cao trong xét nghiệm PAP của nhóm tác giả này ${ }^{3}$.

Mối liên quan giữa nhiễm HPV với tế bào âm đạo cổ tử cung bất thường: Nguy cơ bất thường tế bào cổ tử cung cao gấp 2,5 lần ở người bị nhiếm HPV so với người không nhiễm $(\mathrm{OR}=2,5 ; 95 \% \mathrm{CI}: 1,4-4,5)$. Theo nghiên cứu của Nguyễn Thị Hồng Nga, phụ nữ nhiễm HPV nguy cơ cao bị bất thường cổ tử cung tăng gấp 8,5 lần so với người có kết quả âm tính (OR = 8,5, 95\% CI: 6, $79-10,73)^{8}$. Kết quả nghiên cứu của chúng tôi thấp hơn nghiên cứu của Nguyễn Thị Hồng Nga tại cùng một bệnh viện.

\section{KẾT LUẬN}

Có $76,4 \%$ bệnh nhân có tế bào âm đạo cổ tử cung bất thường bi nhiễm HPV nguy cơ cao trong đó: $37,1 \%$ nhiễm $1 / 12$ Typ chiếm tỷ lệ cao nhất; $17,8 \%$ nhiễm Typ 16; 6,2\% nhiếm Typ 18; $15,4 \%$ nhiếm đa nhiếm tức là nhiếm từ 2 typ trớ lên trong số Typ 16, Typ 18, 1/12 Typ khác. Tỷ lệ tế bào âm đạo cổ tử cung bất thường: $0,8 \%$ là ung thư tế bào vảy; $18,5 \%$ có tế bào là HSIL; $42,9 \%$ có tổn thương LSIL chiếm tỷ lệ cao nhất; $34,4 \%$ là tế bào phản ứng $(30,5 \%$ là $\mathrm{ASC}$ và $3,9 \%$ là $A G C)$

Có mối liên quan chặt chẽ giữa nhiễm HPV với tế bào âm đạo cổ tử cung bất thường: $85,6 \%$ nhóm LSIL có nhiễm HPV; $81,3 \%$ nhóm HSIL có nhiễm HPV $(\mathbf{p}<\mathbf{0 , 0 5})$

Nguy cơ ung thư cổ tử cung tăng 2,5 lần ở nhóm nhiễm HPV so với nhóm không bị nhiễm HPV (OR = 2,5; 95\%CI: $1.4-4,5)$.

\section{TÀI LIÊU THAM KHẢO}

1. Bruni $L$ B-RL, Albero $G$, Aldea $M$, Serrano $B$, Valencia S, Brotons $M$, Mena $M$, Cosano $R^{\prime}$, Munoz J, Bosch FX, de Sanjose' S, Castellsague' $\mathbf{X}$. Human Papilomavirus and Related Diseases in the World, Catalan Insitute of Oncology Information Centre on HPV and Cancer. 
2. Bộ y tế-Vskbmt. Kễ hoạch hành động quốc gia dự phòng và kiểm soát ưng thư cổ tư cung giai đoan 2016-2025. 2016.

3. Lê Quang Vinh LTH. Phát hiện tỉ lệ nhiễm HPV và tế bào cổ tử cung bất thường ở phụ nữ Thái Nguyên. Tạp chí nghiên cứu y học. 2013:3. 3.

4. Trương Quang Vinh. Nghiên cứu nhiểm Human Papilloma virus ở các phụ nữ có các tổn thương tiền ung thư và ung thư cổ tử cung, . Trường Đại hoc Y Dước, Đai hoc Huế. 2010.

5. J. Thomas Cox MPEC, PhD, MPH; Catherine M. Behrens, MD, PhD; Abha Sharma, PhD;Thomas C. Wright Jr, MD; Jack Cuzick, PhD;. and the Athena HPV Study Group, (2012), Comparison of cervical cancer screening strategies incorporating different combinations of cytology, HPV testing, and genotyping for HPV 16/18: results from the ATHENA HPV study. American Journal of Obstetrics and Gynecology 2012.

6. Phạm Thị Ngọc Xuấn TTL. Tầm soát ung thư cổ tử cung tại các xã huyên Thủ Thửa tỉnh Long An. Tạp chí y học thành phổ Hồ Chí Minh. 2008;1:12.

7. NatachaPhoolcharoen $\mathbf{N}$, ThaniyaSricharunrat, SiripornSaeloo, WaraphornKrongthong (2017). A population-based study of cervical cytology findings and human papillomavirus infection in a suburban area of Thailand. Gynocologic oncology report. 2017:21:73.

8. Nguyến Thị Hồng Nga. Khảo sát mối liên quan giữa nhiễm HPV nguy cơ cao với các tổn thương tiền ung thư và ung thư cổ tử cung tai bênh viện phụ sản trung ương. Đại học Y Hà Nội 2017.

\section{ĐÁNH GIÁ KẾT QUẢ TAOO HİNH HỆ THỐNG XƯƠNG CON VÀ TẠO HİNH MÀNG NHĨ BẰNG SỤN TRÊN BỆNH NHÂN VIÊM TAI DÍNH}

\section{TÓM TẮT}

Sử dụng phương pháp mô tả từng trường hợp có can thiệp nhằm đánh giá kết quả sau tạo hình hệ thống xương con và phục hồi màng nhĩ bằng sụn. Kết quả: Tuổi thường gặp 40,06 \pm 11.06 tuổi. Nữ nhiều hơn nam. Triêu chứng cơ năng thường găp ù tai, nghe kém. Nội soi tai $50 \%$ viêm tai dính toà̃n bộ, $50 \%$ viêm tai dính khu trú. Thính lực trước phẫu thuật ngưỡng nghe đường xương là 15,78 $\pm 12,50 \mathrm{~dB}$, PTA trung bình trước phẫu thuất là $43,36 \pm 17,45 \mathrm{~dB}$, chỉ số $\mathrm{ABG}$ trước phẫu thuật là $27,65 \pm 13,71 \mathrm{~dB}$. Chụp cắt lớp vi tính chuỗi xương con liên tục ở 10/16 BN chiếm $62,5 \%$, chuỗi xương con bị gián đoạn ở 6/16 BN chiếm $37,5 \%$. Tổn thương xương con trong viêm tai dính: $100 \%$ tổn thương xương đe, $31,25 \%$ tổn thương cả hỗn hợp búa đe, không có trường hợp nào tổn thương cả 3 xương con. Phục hồi màng nhĩ bằng sụn và màng sụn trong $81,25 \%$, kết hợp sụn và cân cơ thái dương trong $18,75 \%$ trường hợp. Thời gian theo dõi trung bình sau phẫu thuật là $9,6 \pm 7,2$ tháng. Sau mổ $75 \%$ cải thiện tình trạng ù tai và nghe kém. Ngưỡng nghe đường khí trung bình sau phẫu thuật là $33,59 \pm 14,90 \mathrm{~dB}$, chỉ số $\mathrm{ABG}$ sau phẫu thuât là 23,98 $\pm 14,3 \mathrm{~dB}$. Kết luận: Phẫu thuật tạo hình hệ thống xương con và phục hồi màng nhĩ bằng sụn là phương pháp căn bản điều trị viêm tai dính và tái tạo chức năng nghe. sụn

Tư khóa: viêm tai dính, phục hồi màng nhĩ bằng

\footnotetext{
${ }^{1}$ Bệnh viện Đa khoa Đông Anh

${ }^{2}$ Trường Đại học Y Hà Nội

Chiu trách nhiệm chính: Trịnh Đắc Chung

Email: trinhdacchung@gmail.com

Ngày nhận bài: 13.9.2021

Ngày phản biên khoa họ: 10.11.2021

Ngày duyệt bài: 17.11.2021
}

\section{Trịnh Đắc Chung ${ }^{1}$, Nguyễn Thị Tố Uyên ${ }^{2}$}

\section{SUMMARY}

ASSESSMENT OF THE RESULTS OF OSSICULAR CHAIN RECONSTRUCTION AND CARTILAGE TYMPANOPLASTY IN PATIENTS WITH ADHESIVE OTITIS MEDIA

Using a descriptive case-by-case approach to evaluation of the results of ossicular chain reconstruction and cartilage tympanoplasty. Results: Most patients are at the age of $40.06 \pm 11.06$. Females account for a larger proportion. Symptoms are often tinnitus, hearing loss. Otoscopy results show $50 \%$ of patients having total adhesive otitis media, 50\% others having focal adhesive otitis media. Preoperative hearing threshold is $15.78 \pm 12.50 \mathrm{~dB}$, average PTA before surgery is $43.36 \pm 17.45 \mathrm{~dB}$, preoperative $A B G$ is $27.65 \pm 13.71 \mathrm{~dB}$. Computed tomography shows 10/16 patients, accounting for $62.5 \%$ have continuous ossicular chain, and 6/16 patients accounting for $37.5 \%$ have broken chain. Injury to the ossicles in adhesive otitis media: $100 \%$ of patients have damaged anvils, $31.25 \%$ others have damaged hammer and anvil, no cases have all 3 bones damaged. Cartilage tympanoplasty are applied in $81.25 \%$ of patients, $18.75 \%$ are treated with cartilage and temporomandibular fascia. The mean follow-up time is $9.6 \pm 7.2$ months. After surgery, tinnitus and hearing loss are relieved in $75 \%$ of patients. The mean airway threshold after surgery is $33.59 \pm 14.90 \mathrm{~dB}$, and $A B G$ after surgery is $23.98 \pm 14.3 \mathrm{~dB}$.

Keywords. adhesive otitis media, cartilage tympanoplasty.

\section{I. ĐĂT VẤN ĐỀ}

Viêm tai dính là hiện tượng màng nhĩ bị hút và dính vào thành trong hòm nhĩ và chuỗi xương con. Phẫu thuật tạo hình hệ thống xương con và phục hồi màng nhĩ là phương pháp căn bản để điều trị viêm tai dính, và tái tạo lại chức năng 